\title{
The Effect of Transition Metal Doping on the Photooxidation Process of Titania-Clay Composites
}

\author{
Judit Ménesi, ${ }^{1}$ Renáta Kékesi,, ${ }^{1}$ László Körösi, ${ }^{1}$ Volker Zöllmer, ${ }^{2}$ André Richardt, ${ }^{3}$ and Imre Dékány ${ }^{1}$ \\ ${ }^{1}$ Department of Colloid Chemistry, Supramolecular and Nanostructured Materials Research Group of Hungarian Academy of Sciences, \\ University of Szeged, H-6720 Szeged, Aradi Vertanuk tere 1, Hungary \\ ${ }^{2}$ Fraunhofer Institute for Manufacturing and Advanced Materials (IFAM), Functional Structures, Wiener Strasse 12, \\ 28359 Bremen, Germany \\ ${ }^{3}$ German Armed Forces Scientific Institute for Protection Technologies, NBC-Protection, 29623 Munster, Germany
}

Correspondence should be addressed to Imre Dékány, i.dekany@chem.u-szeged.hu

Received 8 September 2007; Accepted 23 November 2007

Recommended by M. Sabry A. Abdel-Mottaleb

Montmorillonite- $\mathrm{TiO}_{2}$ composites containing various transition metal ions (silver, copper, or nickel) were prepared, and their photocatalytic efficiencies were tested in the degradation of ethanol vapor at 70\% relative humidity. Two light sources, UV-rich $(\lambda=254 \mathrm{~nm})$ and visible $(\lambda=435 \mathrm{~nm})$, were used. The kinetics of degradation was monitored by gas chromatography. It was established that, in the case of each catalyst, ethanol degradation was more efficient in UV-C $(\lambda=254 \mathrm{~nm})$ than in visible light, furthermore, these samples containing silver or copper ions were in each case about twice more efficient than $\mathrm{P}_{25} \mathrm{TiO}_{2}(\mathrm{Degussa}$ AG.) used as a reference. In photooxidation by visible light, $\mathrm{TiO}_{2} /$ clay samples doped with silver or copper were also more efficient than the reference sample, $\mathrm{P} 25 \mathrm{TiO}_{2}$. We show that doping metal ions can also be delivered to the surface of the support by ion exchange and significantly alters the optical characteristics of the $\mathrm{TiO}_{2} /$ clay composite.

Copyright (C) 2008 Judit Ménesi et al. This is an open access article distributed under the Creative Commons Attribution License, which permits unrestricted use, distribution, and reproduction in any medium, provided the original work is properly cited.

\section{INTRODUCTION}

The photocatalytic degradation of volatile organic components (VOCs) by UV light in the presence of $\mathrm{TiO}_{2}$ catalysts has been the subject of numerous publications $[1-10]$. $\mathrm{TiO}_{2}$ is one of the most efficient photocatalysts; however, since semiconductor particles are in need of the higher energy content of UV light, a mere $5 \%$ of sunlight is utilized in the course of irradiation for excitation of the catalyst. Absorption by photocatalysts in the visible range can be significantly improved by incorporation of metal ions; however, photoactivity is highly dependent on the chemical nature and the concentration of the dopingion and on the method of preparation. Dvoranová et al. [11] incorporated cobalt, chrome, and manganese ions into the crystalline structure of $\mathrm{TiO}_{2}$ using the sol-gel method. Although the presence of the doping ions caused a significant absorption shift in the visible range relative to pure P25 titanium dioxide, the photocatalytic activity of the catalysts decreased considerably. Chiang et al. [12] prepared Degussa $\mathrm{P} 25 \mathrm{TiO}_{2}$ doped with $\mathrm{CuO}$ by photodeposition for the purpose of liquid-phase degradations; the presence of $\mathrm{Cu}^{2+}$ ions, however, again decreased photocatalytic efficiency. $\mathrm{TiO}_{2}$ doped with $\mathrm{CuO}$ was also prepared by Slamet et al. [13], and enhanced photocatalytic effect was observed only at a single optimal $\mathrm{Cu}(\mathrm{II})$ ion content. Copper is an efficient electron trap and is therefore capable of inhibiting recombination of electron-hole pairs, thereby significantly increasing efficiency.

It has been proven by many reports that the reaction rate is dependent on how the component to be destroyed can be concentrated on the surface of $\mathrm{TiO}_{2}[14,15]$. $\mathrm{TiO}_{2}$-pillared clay minerals, these novel photocatalysts, attract attention by their ability to accelerate the photocatalytic reaction by their unique adsorption capabilities $[16,17]$. This increased absorbability is the result of the large specific surface area produced by the incorporation of $\mathrm{TiO}_{2}$ particles among the silicate layers, creating a mesoporous structure. Liu et al. [18] obtained an $\mathrm{Ag}-\mathrm{TiO}_{2}$ / montmorillonite composite by hydrolysis of $\mathrm{TiCl}_{4}$ and, due to the large specific surface area and the effect of silver content to improve light absorption, they observed an increased photooxidation activity as compared to the reference material, $\mathrm{TiO}_{2}$. Kun et al. [19] established that 
$\mathrm{TiO}_{2} /$ montmorillonite nanocomposites pillared with $\mathrm{TiO}_{2}$ nanoparticles exhibit outstanding catalytic activity in phenol degradation.

Volatile organic components are being widely utilized not only for industrial but also for household purposes, leading to water and air pollution. Photocatalytic degradation of ethanol has been discussed in detail in a number of studies [20-22]. Nimlos et al. [23] studied the mechanism of degradation and established the following sequence of products: ethanol $\rightarrow$ acetaldehyde $\rightarrow$ acetic acid $\rightarrow$ formaldehyde $\rightarrow$ formic acid $\rightarrow \mathrm{CO}_{2}$, with acetaldehyde as the main intermediate. Sauer and Ollis studied deactivation of Degussa P25 $\mathrm{TiO}_{2}[24,25]$. In the presence of water vapor, intermediates and/or products may accumulate on the surface of the catalyst and deactivate it. Since water is one of the products of the reaction, the reaction rate decreases continuously due to deactivation.

Our objective was the production of catalysts also efficient in the visible range. As shown by the references above, incorporation of metal ions into $\mathrm{TiO}_{2}$ is not always expedient; we therefore prepared composites with the transition metal ions incorporated not directly on the surface or into the crystalline structure of $\mathrm{TiO}_{2}$, but into the clay mineral acting as support. When the photocatalyst $\mathrm{TiO}_{2}$ is mixed to or ground with the clay mineral support, the result is a $\mathrm{TiO}_{2}$ /layer silicate composite held together by electrostatic forces [19]. We study the catalytic properties of the ionexchanged composite, obtained in this way in ethanol degradation on the solid/gaseous interface at 70\% relative humidity, to appropriately model local environmental conditions in the photocatalytic reaction.

\section{EXPERIMENTAL}

\subsection{Materials}

Starting materials for the preparation of composites were Degussa $\mathrm{P} 25 \mathrm{TiO}_{2}$ and the fine fraction of $\mathrm{Na}$-montmorillonite EXM-838 ( $d<2$ nm, Süd-Chemie AG, Munich, Germany) - The following nitrates were used for ion exchange in clay minerals: nickel nitrate (Fluka Chemie GmbH, Buchs, Switzerland), copper nitrate (LightTech, Dunakeszi, Hungary), and silver nitrate (LightTech, Dunakeszi, Hungary). Vapor phase degradation was performed using 99.8\% anhydrous ethanol (LightTech, Dunakeszi, Hungary).

\subsection{Preparation of transition metal exchanged montmorillonite/TiO $\mathrm{T}_{2}$ composites}

One gram of Na-montmorillonite (EXM838) was left to swell in $100 \mathrm{~mL}$ of distilled water for 1 day. The next day, $1 \mathrm{mmol}$ of $\mathrm{Ag}(\mathrm{I})$ nitrate or $0.5 \mathrm{mmol}$ of $\mathrm{Ni}$ (II) and $\mathrm{Cu}$ (II) nitrate were added to the montmorillonite swollen in distilled water, the volume of the medium was brought up to $500 \mathrm{~mL}$ by the addition of distilled water, and the suspension was left to stand in a hot air thermostat at $35^{\circ} \mathrm{C}$ for 2 days. The precipitate obtained was next washed 3 times in distilled water, centrifuged and dried at $65^{\circ} \mathrm{C}$. The composite was prepared by grinding, for 30 minutes in an agate mortar, a powder mixture consist-

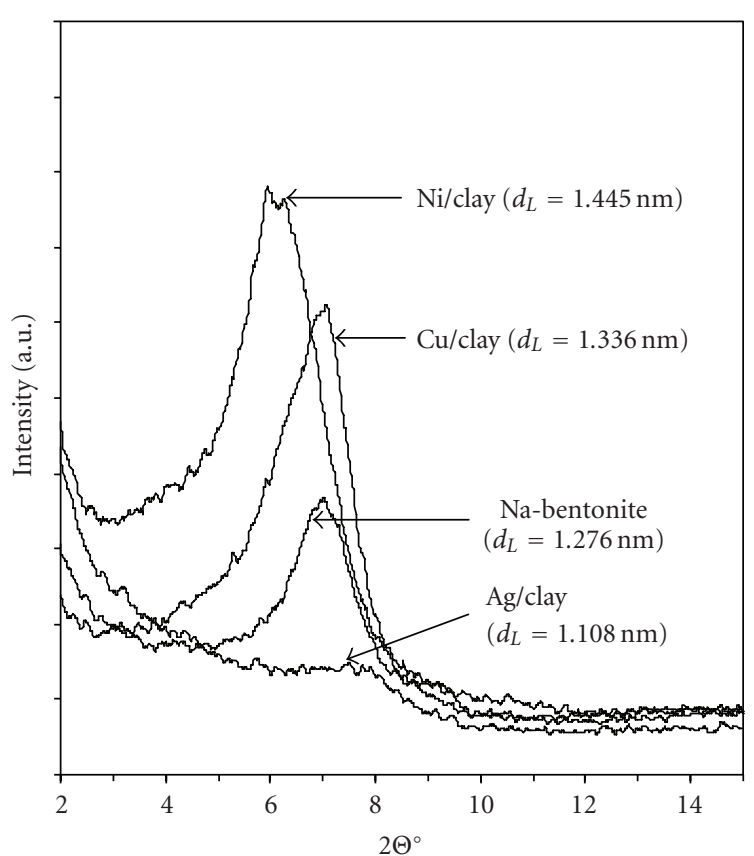

(a)

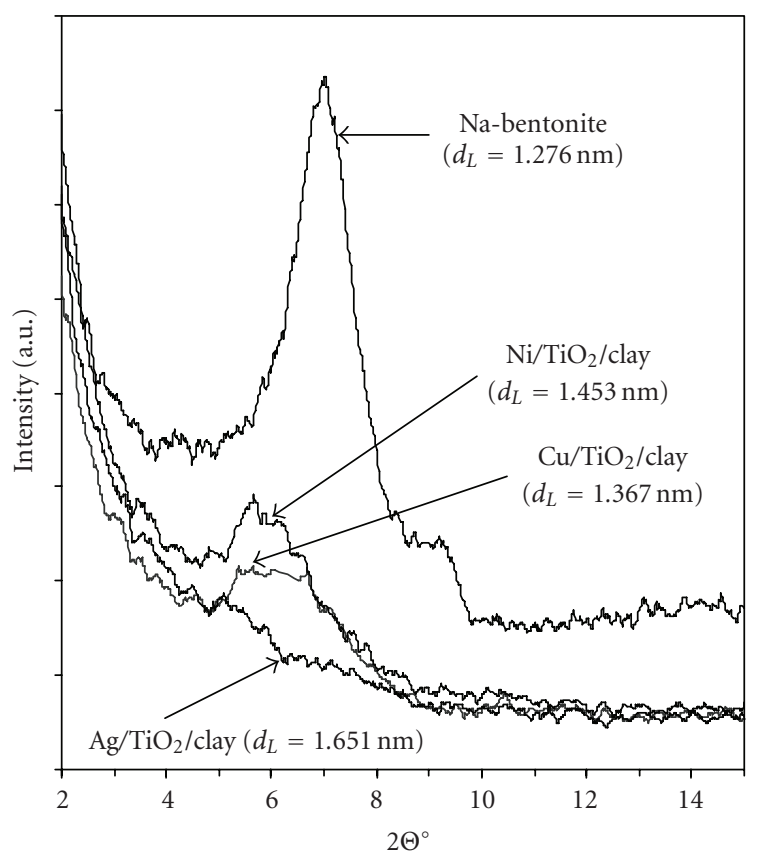

(b)

Figure 1: X-ray diffraction (XRD) patterns of (a) Me/clay and (b) $\mathrm{Me} / \mathrm{TiO}_{2} /$ clay samples.

ing of $20 \%$ exchanged transition metal-montmorillonite and $80 \% \mathrm{P} 25 \mathrm{TiO}_{2}$. Metal contents relative to the total mass of the catalyst were Ag: $2.16 \%$, Cu: $0.64 \%$, and Ni: 0.59\%.

\subsection{Structure properties}

The XRD experiments (Figure 1) were carried out in a Philips X-ray diffractometer (PW 1830 generator, PW 1820 

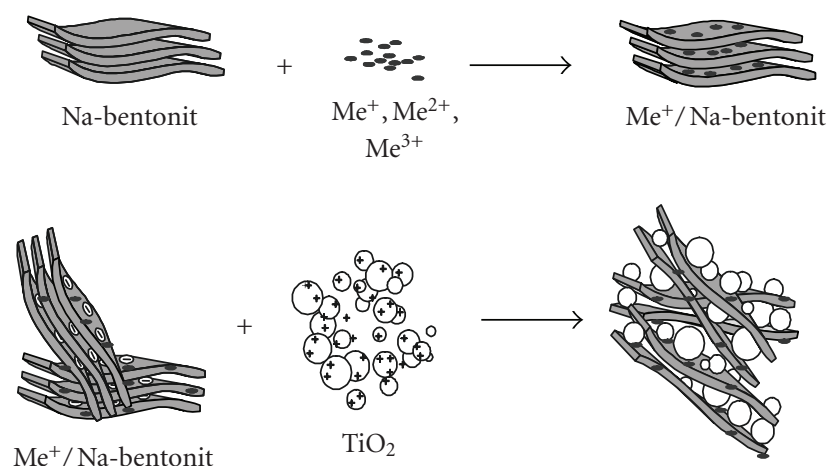

$\mathrm{Me}^{+} / \mathrm{Na}$-bentonit / $\mathrm{TiO}_{2}$

FIGURE 2: Schematic drawing of preparation of Me-ion exchanged montmorillonite/ $\mathrm{TiO}_{2}$ composites.

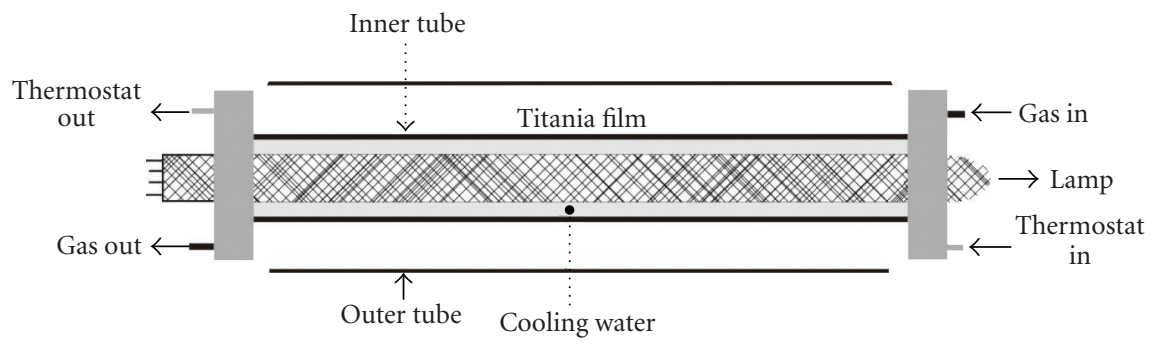

FIgURE 3: Schematic drawing of the photoreactor.

goniometer) with CuK- $\alpha$ radiation $(\lambda=0.1542 \mathrm{~nm}) 40 \mathrm{kV}$, $35 \mathrm{~mA}$. The basal spacing $\left(d_{L}\right)$ was calculated from the $(001)$ reflection via the Bragg equation using the PW 1877 automated powder diffraction software. The analyses were carried out at ambient temperature in the $1-15^{\circ}(2 \Theta)$ ranges. The $1-$ $15^{\circ}(2 \Theta)$ ranges are characteristic of the structure of the layer silicate.

\subsection{Optical properties}

A Mikropack Nanocalc 2000 spectrophotometer equipped with an integrated sphere (ISP-50-8-R-GT) was used to record the diffuse reflectance spectra of the samples. The spectra of the samples were analyzed under ambient condition in the wavelength range of $350-700 \mathrm{~nm}$. The optical properties of transition metal-loaded titania/clay catalysts are listed in Table 1.

\subsection{Photocatalytic reactions}

Photooxidation of ethanol was performed in the reactor (volume: ca. $700 \mathrm{~mL}$ ) at $25 \pm 0.1^{\circ} \mathrm{C}$. The experimental setup is described in our previous paper [26]. The photoreactor (Figure 3 ) consists of two concentrically positioned tubes, namely, an inner quartz tube and an outer Pyrex glass tube. The light sources of the reactor were two types of $15 \mathrm{~W}$ low-pressure mercury lamp (LightTech, Dunakeszi, Hungary), namely, a GCL307T5L/CELL type (light source 1) with characteristic emission wavelength at $\lambda_{\max }=254 \mathrm{~nm}$ and a GCL303T5 S\#2 type (light source 2) with characteristic emission wavelength at $\lambda_{\max }=435 \mathrm{~nm}$. The catalyst was sprayed onto the outer side of the inner quartz tube from 10 to $20(\mathrm{~m} / \mathrm{v}) \%$ aqueous dispersion using $\mathrm{N}_{2}$ stream. The surface of the catalyst film was $44.8 \mathrm{~cm}^{2}$, and the catalyst mass per unit surface was $0.310 \pm 0.03 \mathrm{mg} / \mathrm{cm}^{2}$. The film thickness was ca. $0.7-1.0 \mu \mathrm{m}$. The reactor was filled with dry synthetic air $\left(\left[\mathrm{H}_{2} \mathrm{O}\right]<5 \mathrm{ppm}\right)$ to a final pressure of 760 Torr. After the delivery of $10 \mu \mathrm{L}$ ethanol and $12 \mu \mathrm{L}$ water, the system was left to stand for 30 minutes for evaporation of the components and establishment of the adsorption equilibrium. The reaction starts with switching on the lamp. Sampling from the gas phase $(1 \mathrm{~mL})$ was performed at selected time intervals, and the composition was analyzed in a gas chromatograph (Shimadzu GC-14B) equipped with a thermal conductivity (TCD) and a flame ionization detector (FID). The temperature of the column (HayeSep Q, length $2 \mathrm{~m}$ ) was $140^{\circ} \mathrm{C}$. A sample volume of $1 \mathrm{~mL}$ was introduced through a sixway valve to the online GC used for quantitative analysis of ethanol, acetaldehyde, and $\mathrm{CO}_{2}$. A membrane pump inserted into the experimental assembly circulates the gas mixture to be degraded through the flow meter, the reactor, and the sampler of the gas chromatograph. The flow rate of the gas mixture in the measuring system was $375 \mathrm{~mL} / \mathrm{min}$. The initial concentration of ethanol was $0.25 \mathrm{mmol} \mathrm{dm}^{-3}$ at relative humidity of $\sim 70 \%$.

\section{RESULTS}

Showing the XRD pattern, we can establish that for the sodium montmorillonite, characteristic Bragg peak at $2 \Theta^{\circ}=$ $7.02^{\circ}$ appears and the basal distance is $d_{001}=1.276 \mathrm{~nm}$. After 
TABLE 1: The composition and optical properties of the catalysts.

\begin{tabular}{lccrc}
\hline & Metal content (mequ/g clay) & Metal content $(\mathrm{wt} \%)$ & $\lambda_{g}(\mathrm{~nm})$ & 390 \\
\hline $\mathrm{TiO}_{2}(\mathrm{P} 25)$ & 0.00 & 0.00 & $E_{g}(\mathrm{eV})$ \\
\hline $\mathrm{Ag} / \mathrm{TiO}_{2} /$ clay & 1.00 & 2.16 & 455 & 3.18 \\
\hline $\mathrm{Ni} / \mathrm{TiO}_{2}$ /clay & 1.00 & 0.59 & 401 & 3.73 \\
$\mathrm{Cu} / \mathrm{TiO}_{2}$ /clay & 1.00 & 0.64 & 404 \\
\hline
\end{tabular}

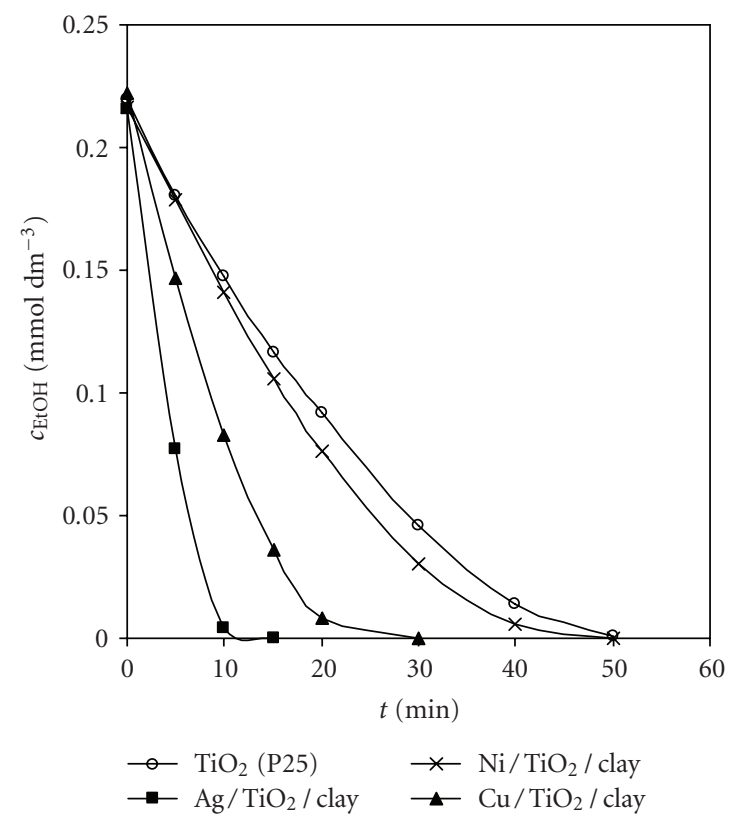

(a)

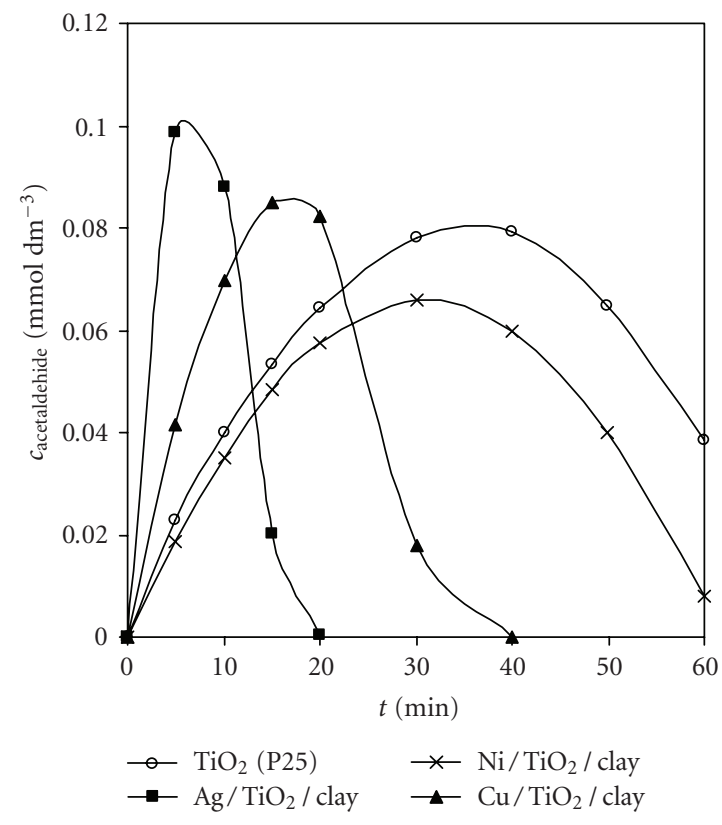

(b)

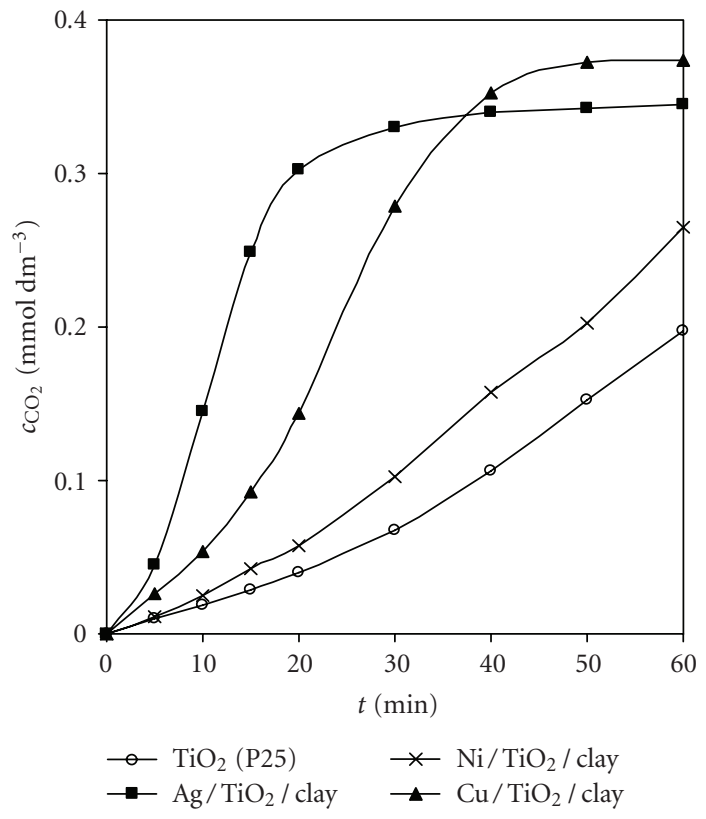

(c)

FIGURE 4: Ethanol concentration changes under (a) UV-Vis irradiation (light source 1), (b) kinetic curves of acetaldehyde, and (c) $\mathrm{CO}_{2}$ formation. 


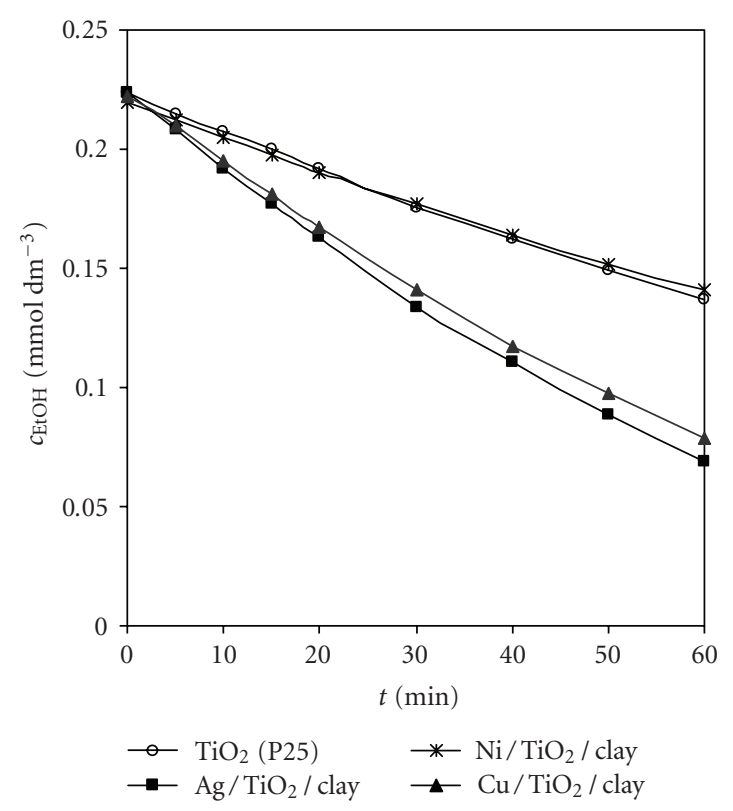

(a)

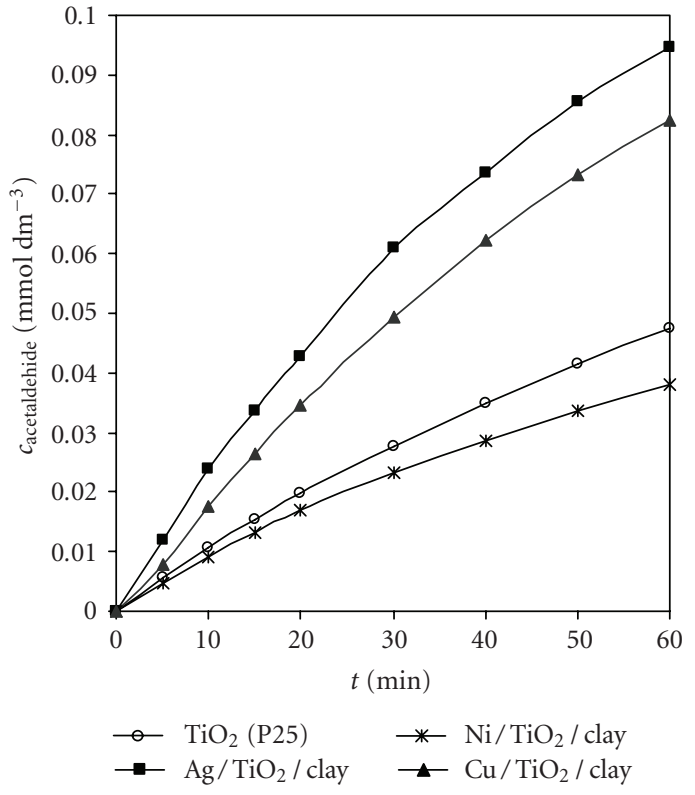

(b)

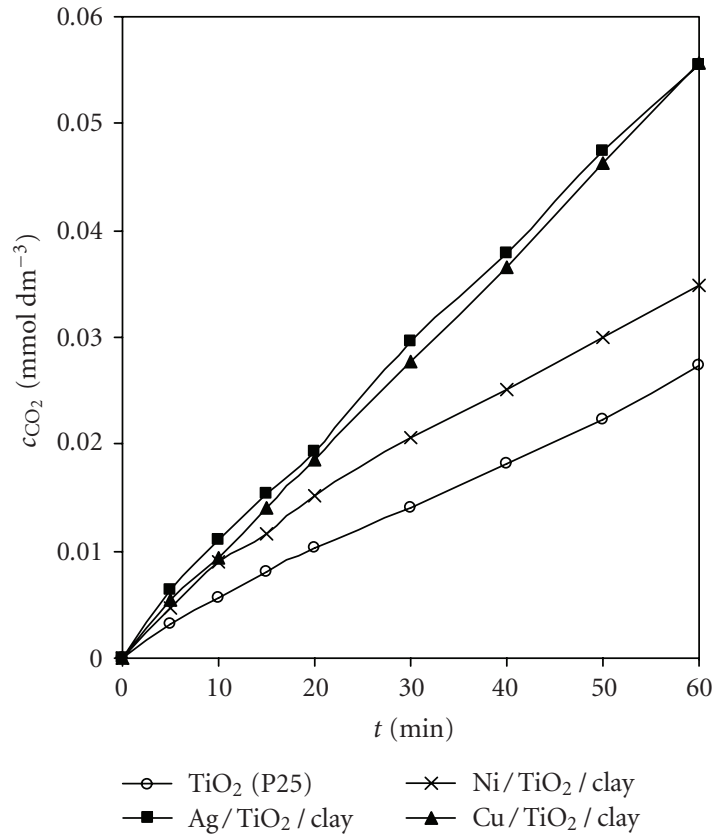

(c)

FIGURE 5: Ethanol concentration changes under (a) visible irradiation (light source 2), (b) kinetic curves of acetaldehyde, and (c) $\mathrm{CO}_{2}$ formation.

the exchange of $\operatorname{Ag}(\mathrm{I})$ ions, the intensity of this reflection is lower and $d_{001}=1.108 \mathrm{~nm}$ because the layered structure will be partially disoriented. However, in the case of $\mathrm{Cu}(\mathrm{II})$ - and $\mathrm{Ni}(\mathrm{II})$-ions modified montmorillonite samples, the basal distance is $1.336 \mathrm{~nm}$ and $1.445 \mathrm{~nm}$, respectively (Figure 1(a)); that means the nickel and copper ions can be incorporated between the silicate layers, and the two valent cations can close the layers together producing well-oriented lamel- lar structures. After mixing these modified transition metal montmorillonits with $\mathrm{TiO}_{2}$ powder, the intensity of the clay reflections will be very small, and the interlayer distance will increase to $d_{001}=1.651 \mathrm{~nm}\left(\mathrm{Ag} / \mathrm{TiO}_{2} /\right.$ clay $), d_{001}=1.453 \mathrm{~nm}$ $\left(\mathrm{Ni} / \mathrm{TiO}_{2} /\right.$ clay $)$, and $d_{001}=1.367 \mathrm{~nm}\left(\mathrm{Cu} / \mathrm{TiO}_{2} /\right.$ clay $)$, showing the possibility of the partial incorporation of any $\mathrm{TiO}_{2}$ nanoparticles between the lamellae (Figure 1(b)). The formation of this suggested structures is presented in Figure 2. 
TABLE 2: Photocatalytical characterization of the $\mathrm{TiO}_{2}$ (P25) and the transition metal nanocomposite samples.

\begin{tabular}{|c|c|c|c|c|c|c|}
\hline & \multicolumn{3}{|c|}{ "Light source 1" $(\lambda=254 \mathrm{~nm})$} & \multicolumn{3}{|c|}{ "Light source 2" $(\lambda=435 \mathrm{~nm})$} \\
\hline & 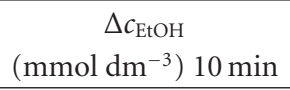 & $\begin{array}{c}k \\
\left(* 10^{-4} \mathrm{~s}^{-1}\right)\end{array}$ & $\begin{array}{c}\text { efficiency } \\
\% \\
\end{array}$ & $\begin{array}{c}\Delta c_{\mathrm{EtOH}} \\
\left(\mathrm{mmol} \mathrm{dm} \mathrm{dm}^{-3}\right) 10 \mathrm{~min}\end{array}$ & $\begin{array}{c}k \\
\left(* 10^{-4} \mathrm{~s}^{-1}\right)\end{array}$ & $\begin{array}{c}\text { efficiency } \\
\%\end{array}$ \\
\hline $\mathrm{TiO}_{2}(\mathrm{P} 25)$ & 0.072 & 6.58 & 100 & 0.017 & 1.43 & 100 \\
\hline $\mathrm{Ag} / \mathrm{TiO}_{2} /$ clay & 0.211 & 34.94 & 293 & 0.032 & 2.31 & 188 \\
\hline $\mathrm{Ni} / \mathrm{TiO}_{2} /$ clay & 0.076 & 6.35 & 105 & 0.015 & 1.22 & 88 \\
\hline $\mathrm{Cu} / \mathrm{TiO}_{2} /$ clay & 0.140 & 13.96 & 194 & 0.027 & 1.88 & 159 \\
\hline
\end{tabular}

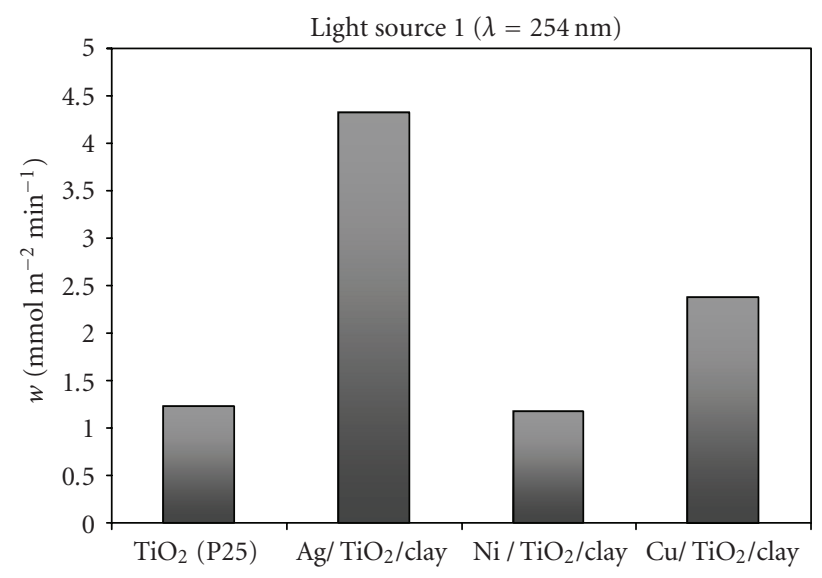

(a)

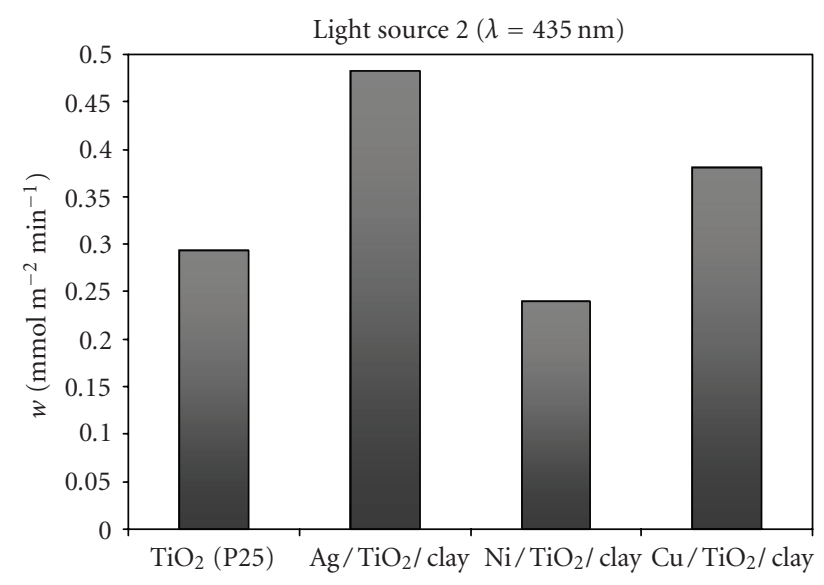

(b)

Figure 6: Amount of degraded ethanol in unit time (1 minute), normalized to a catalyst film surface of $1 \mathrm{~m}^{2}(w)$.

The photocatalytic efficiency of montmorillonite/ $\mathrm{TiO}_{2}$ composites was tested in the degradation of ethanol vapor at $70 \%$ relative humidity. The reference catalyst was pure Degussa $\mathrm{P} 25 \mathrm{TiO}_{2}$. The degradations were also repeated without catalyst with both light sources; it was found that ethanol concentration did not decrease in either case, indicating that self-photolysis does not take place in the vapor studied. The decrease in ethanol concentration and the formation of the main intermediate acetaldehyde were monitored in the course of the measurements (Figures 4(a), 4(b) and 5(a),

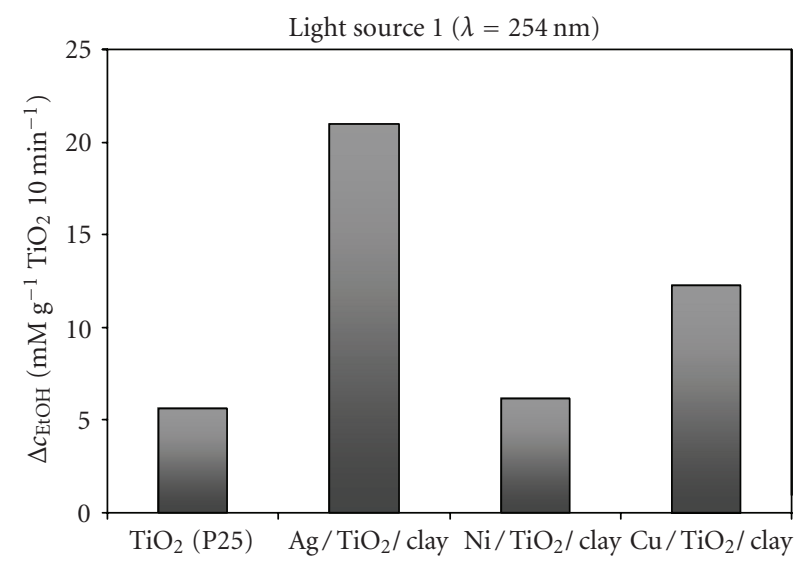

(a)

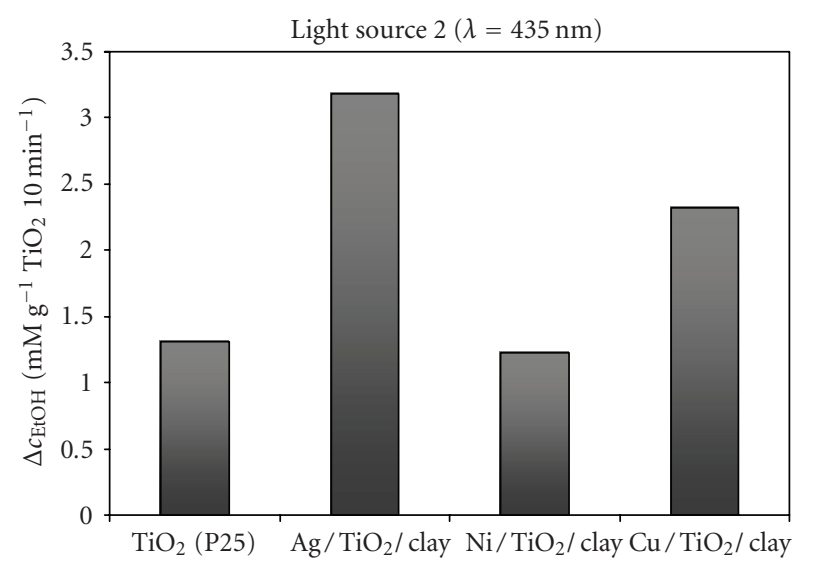

(b)

FIGURE 7: Decreasing of the ethanol concentrations is normalized to $1 \mathrm{~g}$ of $\mathrm{TiO}_{2}$ in unit time (10 minutes).

5(b)). The kinetics of gaseous $\mathrm{CO}_{2}$ formation was also studied (Figures 4(c), 5(c)). The results of the degradations are summarized in Table 2 . In order to characterize catalysts, we introduced the parameter " $w$," which means the amount of ethanol destroyed by irradiation with the given light source in unit time in a reactor volume of $1 \mathrm{dm}^{3}$, normalized to a catalyst film surface of $1 \mathrm{~m}^{2}$ (Figure 6). The parameter $w$ is calculated by the following equation:

$$
w=\frac{\text { amount of degraded } \mathrm{EtOH}\left(\mathrm{mmol} / \mathrm{dm}^{3}\right)}{\text { time }(\min ) * \text { surface }\left(\mathrm{m}^{-2}\right)} .
$$




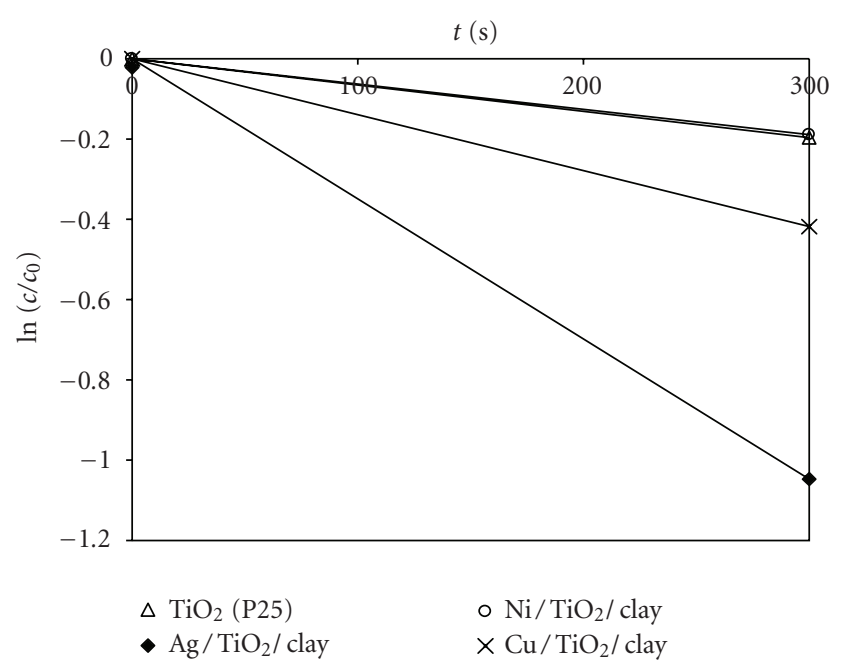

(a)

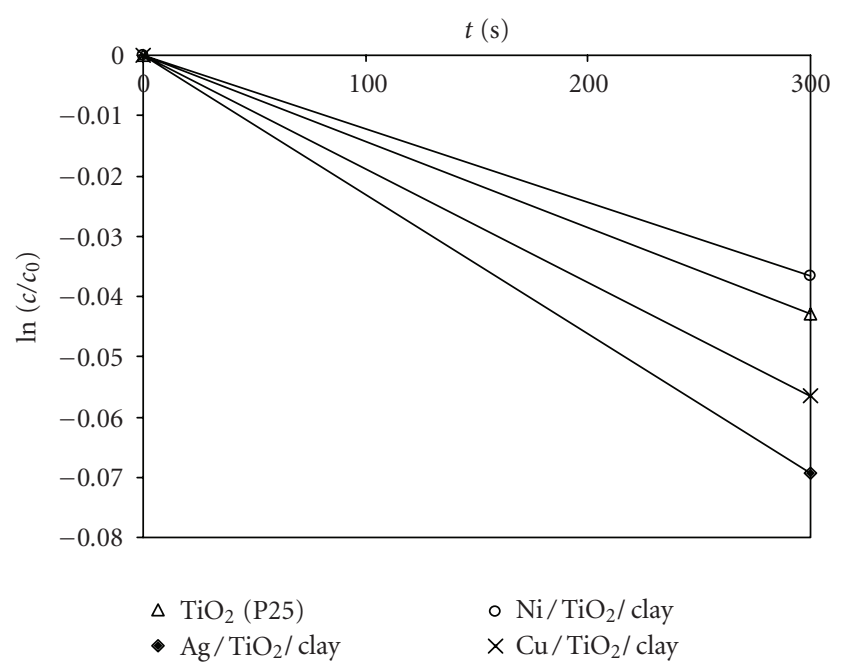

(b)

FIGURE 8: Determination of rate constants $(k)$ with $\ln \left(c / c_{0}\right)$ versus $t$ (sec) function by using (a) "light source 1" and (b) "light source 2" lamps.

The measured $\Delta c_{\mathrm{EtOH}}$ values are normalized to $1 \mathrm{~g}$ of $\mathrm{TiO}_{2}$ catalyst and summarized in Figure 7. Table 2 also includes the rate constants $(k)$ calculated from the slopes of the first-order kinetic functions $\ln \left(c / c_{0}\right)$ versus time. The constants unambiguously indicate that the reactions studied follow first-order kinetics (Figures 8(a), 8(b)).

All in all, it can be established that, in the case of each catalyst, ethanol is destroyed much more efficiently by irradiation with the light source rich in UV-C $(\lambda=254 \mathrm{~nm})$ than in visible light. The reason for this is well known from the literature: the band gap energy of $\mathrm{TiO}_{2}$ is $E_{g}=3.2 \mathrm{eV}$ $\left(\lambda_{g}=387 \mathrm{~nm}\right)$, allowing excitation by light source 1 [27-30]. In the course of photooxidation by both light sources, samples containing silver or copper exhibit higher rates than does the reference $\mathrm{TiO}_{2}$ sample. The composite containing nickel ions degrades ethanol at a higher rate only in the light of the

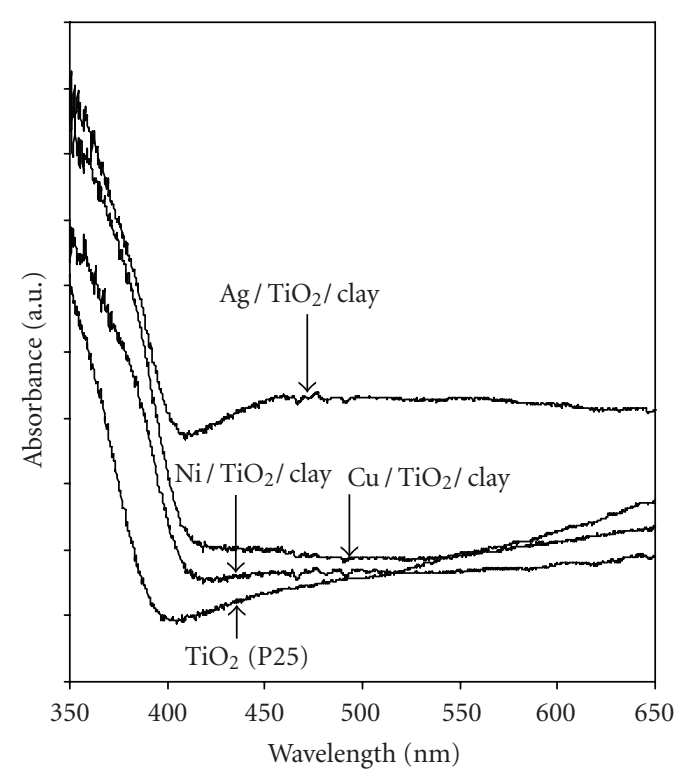

FIGURE 9: Diffuse reflectance UV-Vis spectra of exchanged Namontmorillonite/ $\mathrm{TiO}_{2}$ composites.

source rich in UV-C, whereas its efficiency in visible light is identical with that of the reference sample, P25 $\mathrm{TiO}_{2}$. Efficiencies (Table 2) are calculated from changes in concentration during a 10-minute irradiation time; ethanol degradation effected by the reference sample Degussa $\mathrm{P} 25 \mathrm{TiO}_{2}$ is taken as $100 \%$. The activity of the silver-containing $\mathrm{TiO}_{2} /$ clay composite during irradiation with light source 1 is threefold, and that of the copper-containing composite is twofold over $\mathrm{P} 25 \mathrm{TiO}_{2}$. This extraordinary effect is attributed, on the one hand, to excellent adsorption of ethanol by the layer silicate, allowing fast sorption of ethanol to the $\mathrm{TiO}_{2}$ surface via diffusion [18]. On the other hand, the doping silver and copper, presumably present in the system in the form of silver and copper oxide nanoparticles, respectively $[29,30]$, significantly decrease the rate of electron-hole recombination on the $\mathrm{TiO}_{2}$ surface, increasing catalytic activity. This outstandingly high activity, however, is somewhat decreased in visible light (light source 2), but even in this case, silver and copper degrade ethanol at rates nearly 1.5 -fold faster than does $\mathrm{P} 25 \mathrm{TiO}_{2}$. We assume that the reason for this is an increased photon absorbance in the visible wavelength range $(\lambda=400$ $700 \mathrm{~nm}$ ) on the composites prepared by us, as demonstrated by the absorbance spectra shown in Figure 9. The spectrum of $\mathrm{Ni} / \mathrm{TiO}_{2} /$ clay and $\mathrm{Cu}$-loaded $\mathrm{TiO}_{2} /$ clay displays similar absorbance at wavelengths shorter than $410 \mathrm{~nm}$, while $\mathrm{Cu} / \mathrm{TiO}_{2} /$ clay absorbs more photons whose wavelengths are larger than $410 \mathrm{~nm}$, resulting in the color of light green. The sample of $\mathrm{Ag} / \mathrm{TiO}_{2} /$ clay possesses an additional broadened absorption peak at about $450 \mathrm{~nm}$ in the visible region, that indicates the brown color of the deposited silver can improve the light absorption of $\mathrm{Ag} / \mathrm{TiO}_{2} /$ clay and increase its photocatalytic activity. In other words, the efficiency of degradation in visible light can be explained by the excellent adsorption properties of the layer silicate and the red shift of photon absorbance at higher wavelengths. 


\section{CONCLUSIONS}

Photocatalytic utilization of titanium dioxide and its composites with clay mineral support was studied in a vapor phase oxidation reaction. Since results on direct doping of $\mathrm{TiO}_{2}$ with transient metals reported in the literature did not show an unambiguous increase in efficiency, we used $20 \%$ montmorillonite support exchanged with silver, copper, or nickel ions and mixed/ground with $\mathrm{P} 25 \mathrm{TiO}_{2}$ in powder form. The amounts of metal normalized to the total mass of the catalyst were Ag: $2.16 \%$, Cu: $0.64 \%$, and Ni: $0.59 \%$. The composite obtained was used for the preparation of films on the surface of the glass reactor, where photooxidation was carried out. The rate of photooxidation by irradiation with the light source rich in UV-C $(\lambda=254 \mathrm{~nm})$ increased significantly as a result of the introduction of silver or copper included in the layer silicate, and the rate of the photooxidation process in visible light was also higher than that measured in the presence of the reference sample $\mathrm{P} 25 \mathrm{TiO}_{2}$.

\section{REFERENCES}

[1] P. Pichat, J. Disdier, C. Hoang-Van, D. Mas, G. Goutailler, and C. Gaysse, "Purification/deodorization of indoor air and gaseous effluents by $\mathrm{TiO}_{2}$ photocatalysis," Catalysis Today, vol. 63, no. 2-4, pp. 363-369, 2000.

[2] L. Zhang and J. C. Yu, "A simple approach to reactivate silvercoated titanium dioxide photocatalyst," Catalysis Communications, vol. 6, no. 10, pp. 684-687, 2005.

[3] Z. Guo-Min, C. Zhen-Xing, X. Min, and Q. Xian-Qing, "Study on the gas-phase photolytic and photocatalytic oxidation of trichloroethylene," Journal of Photochemistry and Photobiology A: Chemistry, vol. 161, no. 1, pp. 51-56, 2003.

[4] S. B. Kim, H. T. Hwang, and S. C. Hong, "Photocatalytic degradation of volatile organic compounds at the gas-solid interface of $\mathrm{a}^{\mathrm{TiO}}{ }_{2}$ photocatalyst," Chemosphere, vol. 48, no. 4, pp. 437-444, 2002.

[5] G. Marcí, M. Addamo, V. Augugliaro, et al., "Photocatalytic oxidation of toluene on irradiated $\mathrm{TiO}_{2}$ : comparison of degradation performance in humidified air, in water and in water containing a zwitterionic surfactant," Journal of Photochemistry and Photobiology A: Chemistry, vol. 160, no. 1-2, pp. 105114, 2003.

[6] Z. Pengyi, L. Fuyan, Y. Gang, C. Qing, and Z. Wanpeng, "A comparative study on decomposition of gaseous toluene by $\mathrm{O}_{3} / \mathrm{UV}, \mathrm{TiO}_{2} / \mathrm{UV}$ and $\mathrm{O}_{3} / \mathrm{TiO}_{2} / \mathrm{UV}$," Journal of Photochemistry and Photobiology A: Chemistry, vol. 156, no. 1-3, pp. 189-194, 2003.

[7] T. Sano, N. Negishi, K. Takeuchi, and S. Matsuzawa, "Degradation of toluene and acetaldehyde with Pt-loaded $\mathrm{TiO}_{2}$ catalyst and parabolic trough concentrator," Solar Energy, vol. 77, no. 5, pp. 543-552, 2004.

[8] G.-M. Zuo, Z.-X. Cheng, H. Chen, G.-W. Li, and T. Miao, "Study on photocatalytic degradation of several volatile organic compounds," Journal of Hazardous Materials, vol. 128, no. 2-3, pp. 158-163, 2006.

[9] A. Di Paola, M. Addamo, M. Bellardita, E. Cazzanelli, and L. Palmisano, "Preparation of photocatalytic brookite thin films," Thin Solid Films, vol. 515, no. 7-8, pp. 3527-3529, 2007.
[10] M. Addamo, M. Bellardita, A. Di Paola, and L. Palmisano, "Preparation and photoactivity of nanostructured anatase, rutile and brookite $\mathrm{TiO}_{2}$ thin films," Chemical Communications, no. 47, pp. 4943-4945, 2006.

[11] D. Dvoranová, V. Brezová, M. Mazúr, and M. A. Malati, "Investigations of metal-doped titanium dioxide photocatalysts," Applied Catalysis B: Environmental, vol. 37, no. 2, pp. 91-105, 2002.

[12] K. Chiang, R. Amal, and T. Tran, "Photocatalytic degradation of cyanide using titanium dioxide modified with copper oxide," Advances in Environmental Research, vol. 6, no. 4, pp. 471-485, 2002.

[13] Slamet, H. W. Nasution, E. Purnama, S. Kosela, and J. Gunlazuardi, "Photocatalytic reduction of $\mathrm{CO}_{2}$ on copperdoped Titania catalysts prepared by improved-impregnation method," Catalysis Communications, vol. 6, no. 5, pp. 313-319, 2005.

[14] K. Mogyorósi, I. Dékány, and J. H. Fendler, "Preparation and characterization of clay mineral intercalated titanium dioxide nanoparticles," Langmuir, vol. 19, no. 7, pp. 2938-2946, 2003.

[15] T. Pernyeszi and I. Dékány, "Photocatalytic degradation of hydrocarbons by bentonite and $\mathrm{TiO}_{2}$ in aqueous suspensions containing surfactants," Colloids and Surfaces A: Physicochemical and Engineering Aspects, vol. 230, no. 1-3, pp. 191-199, 2004.

[16] C. Ooka, H. Yoshida, K. Suzuki, and T. Hattori, "Effect of surface hydrophobicity of $\mathrm{TiO}_{2}$-pillared clay on adsorption and photocatalysis of gaseous molecules in air," Applied Catalysis A: General, vol. 260, no. 1, pp. 47-53, 2004.

[17] R. Kun, M. Szekeres, and I. Dékány, "Photooxidation of dichloroacetic acid controlled by $\mathrm{pH}$-stat technique using $\mathrm{TiO}_{2} /$ layer silicate nanocomposites," Applied Catalysis B: Environmental, vol. 68, no. 1-2, pp. 49-58, 2006.

[18] J. Liu, X. Li, S. Zuo, and Y. Yu, "Preparation and photocatalytic activity of silver and $\mathrm{TiO}_{2}$ nanoparticles/montmorillonite composites," Applied Clay Science, vol. 37, no. 3-4, pp. 275280, 2007.

[19] R. Kun, K. Mogyorósi, and I. Dékány, "Synthesis and structural and photocatalytic properties of $\mathrm{TiO}_{2} /$ montmorillonite nanocomposites," Applied Clay Science, vol. 32, no. 1-2, pp. 99-110, 2006.

[20] J. Araña, J. M. Doña-Rodríguez, O. González-Díaz, et al., "Gas-phase ethanol photocatalytic degradation study with $\mathrm{TiO}_{2}$ doped with $\mathrm{Fe}, \mathrm{Pd}$ and $\mathrm{Cu}$," Journal of Molecular Catalysis A: Chemical, vol. 215, no. 1-2, pp. 153-160, 2004.

[21] D. S. Muggli, J. T. McCue, and J. L. Falconer, "Mechanism of the photocatalytic oxidation of ethanol on $\mathrm{TiO}_{2}$," Journal of Catalysis, vol. 173, no. 2, pp. 470-483, 1998.

[22] E. Piera, J. A. Ayllón, X. Doménech, and J. Peral, "TiO ${ }_{2}$ deactivation during gas-phase photocatalytic oxidation of ethanol," Catalysis Today, vol. 76, no. 2-4, pp. 259-270, 2002.

[23] M. R. Nimlos, E. J. Wolfrum, M. L. Brewer, J. A. Fennell, and G. Bintner, "Gas-phase heterogenous photocatalytic oxidation of ethanol: pathways and kinetic modelling," Environmental Science and Technology, vol. 30, no. 10, pp. 3102-3110, 1996.

[24] M. L. Sauer and D. F. Ollis, "Catalyst deactivation in gas-solid photocatalysis," Journal of Catalysis, vol. 163, no. 1, pp. 215217, 1996.

[25] M. L. Sauer and D. F. Ollis, "Photocatalyzed oxidation of ethanol and acetaldehyde in humidified air," Journal of Catalysis, vol. 158, no. 2, pp. 570-582, 1996. 
[26] L. Kőrösi, A. Oszkó, G. Galbács, A. Richardt, V. Zöllmer, and I. Dékány, "Structural properties and photocatalytic behaviour of phosphate-modified nanocrystalline titania films," Applied Catalysis B: Environmental, vol. 77, no. 1-2, pp. 175-183, 2007.

[27] H. Li, Z. Bian, J. Zhu, Y. Huo, H. Li, and Y. Lu, "Mesoporous $\mathrm{Au} / \mathrm{TiO}_{2}$ nanocomposites with enhanced photocatalytic activity," Journal of the American Chemical Society, vol. 129, no. 15, pp. 4538-4539, 2007.

[28] C. Burda, Y. Lou, X. Chen, A. C. S. Samia, J. Stout, and J. L. Gole, "Enhanced nitrogen doping in $\mathrm{TiO}_{2}$ nanoparticles," Nano Letters, vol. 3, no. 8, pp. 1049-1051, 2003.

[29] T. Morikawa, Y. Irokawa, and T. Ohwaki, "Enhanced photocatalytic activity of $\mathrm{TiO}_{2-x} \mathrm{~N}_{x}$ loaded with copper ions under visible light irradiation," Applied Catalysis A: General, vol. 314, no. 1, pp. 123-127, 2006.

[30] I. Dékány, L. Turi, and Z. Király, "CdS, $\mathrm{TiO}_{2}$ and $\mathrm{Pd}^{\circ}$ nanoparticles growing in the interlamellar space of montmorillonite in binary liquids," Applied Clay Science, vol. 15, no. 1-2, pp. 221239, 1999. 


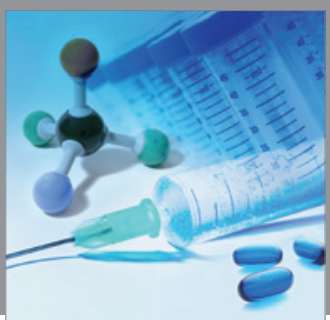

International Journal of

Medicinal Chemistry

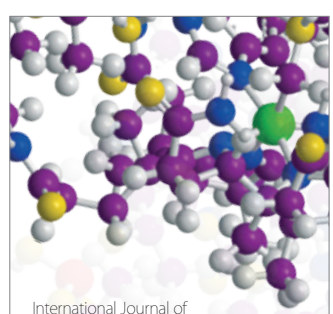

Carbohydrate Chemistry

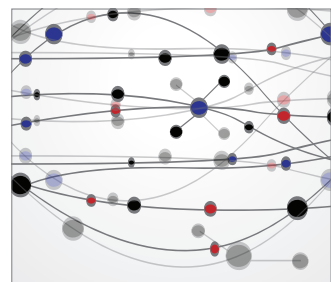

The Scientific World Journal
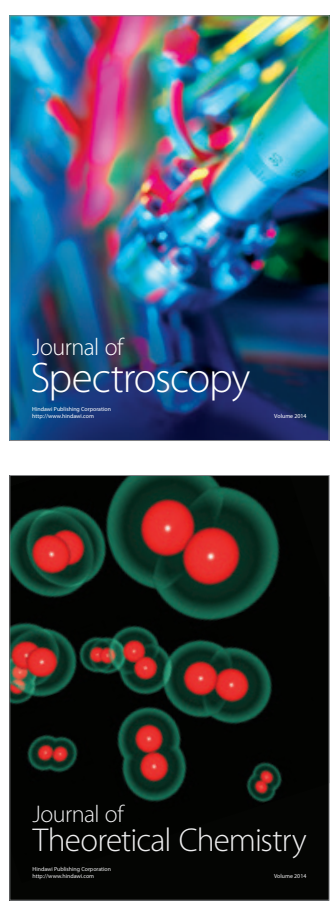
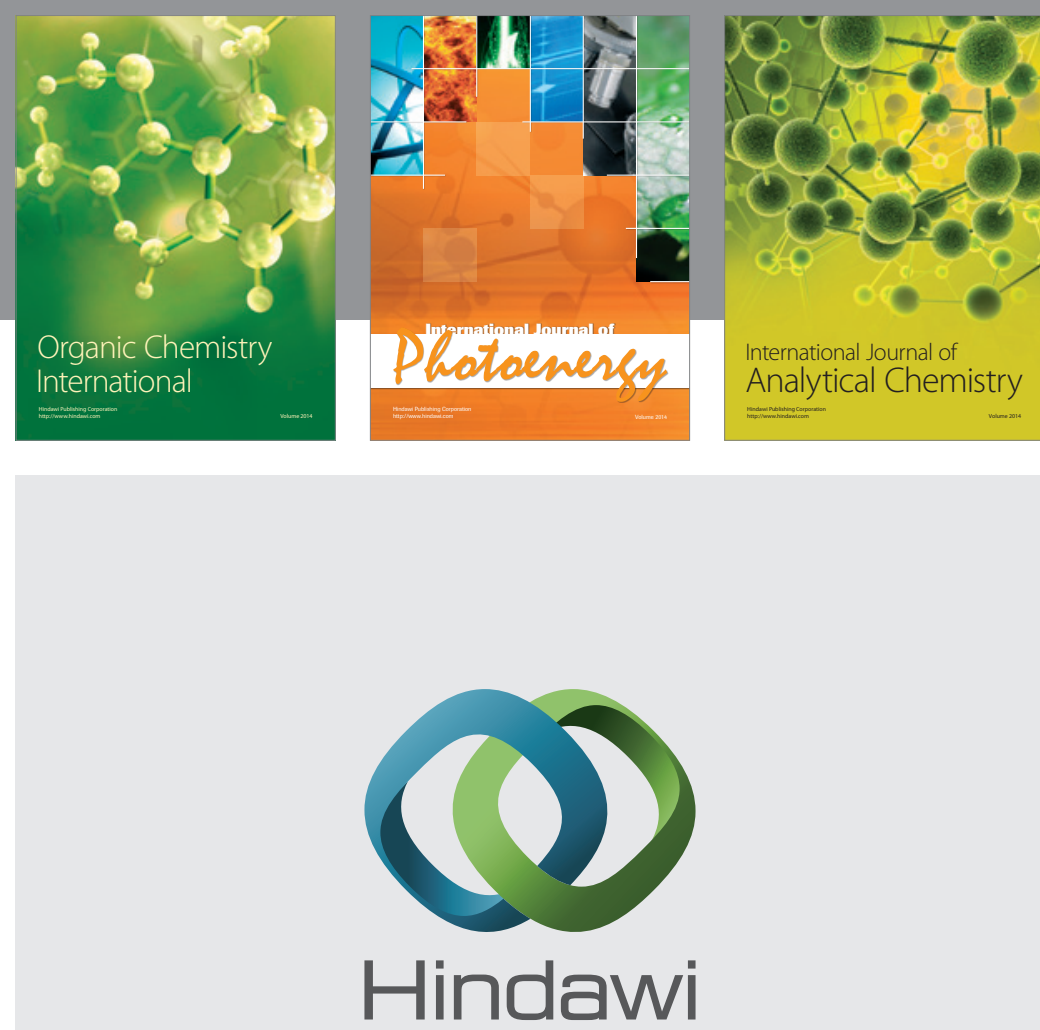

Submit your manuscripts at

http://www.hindawi.com
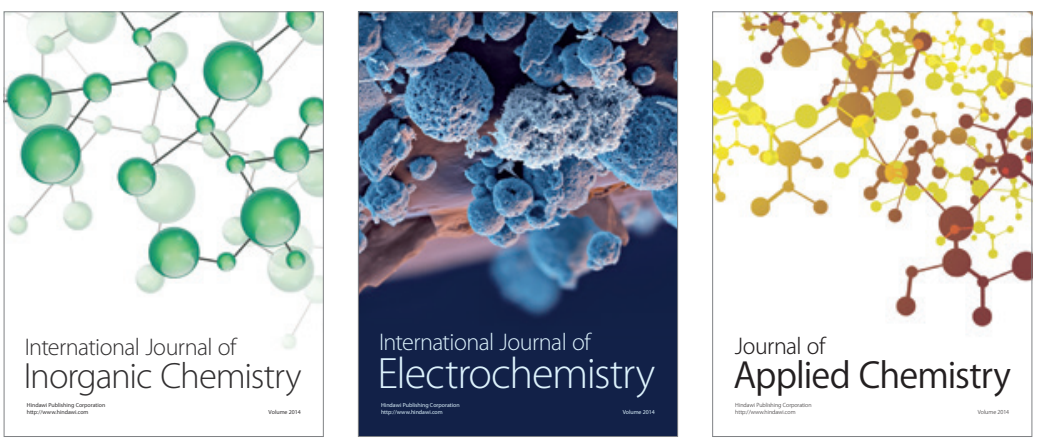

Journal of

Applied Chemistry
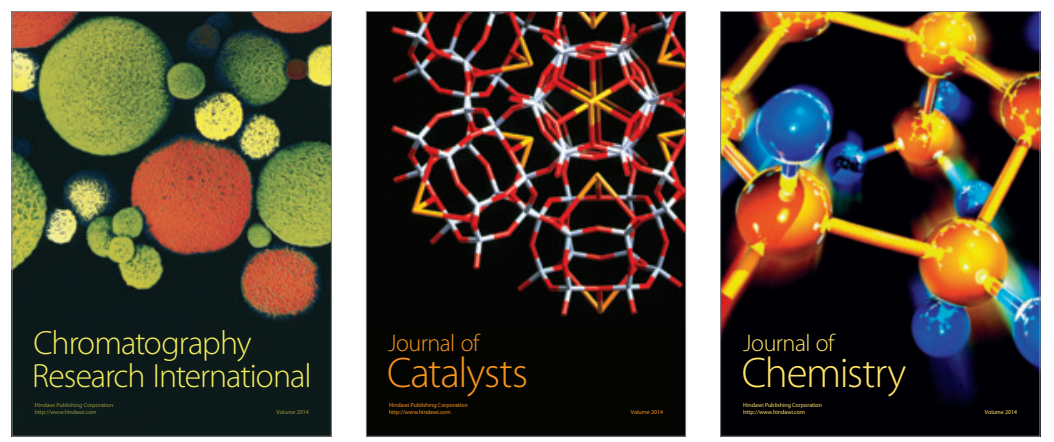
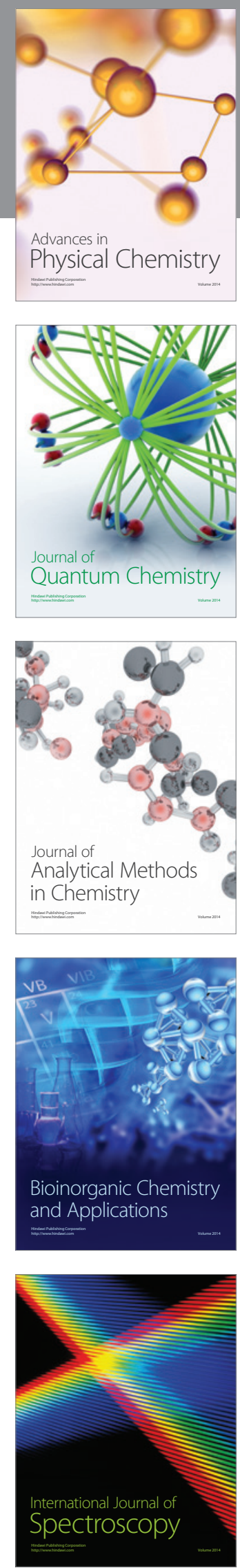